\title{
Using Nintendo Switch Development Environment to Teach Computer Game Programming and Virtual Reality
}

\section{Dr. Arif Sirinterlikci, Robert Morris University}

Arif Sirinterlikci is a University Professor of Industrial and Manufacturing Engineering and the Associate Dean of Research and Outreach at Robert Morris University School of Engineering, Mathematics, and Science. He holds BS and MS degrees, both in Mechanical Engineering from Istanbul Technical University in Turkey and his Ph.D. is in Industrial and Systems Engineering from the Ohio State University. He has been actively involved in ASEE and SME organizations and conducted research in Rapid Prototyping and Reverse Engineering, Biomedical Device Design and Manufacturing, Automation and Robotics, and CAE in Manufacturing Processes fields.

\section{Dr. John M Mativo, University of Georgia}

Dr. John Mativo is Associate Professor at the University of Georgia. His research interest lies in two fields. The first is research focusing on best and effective ways to teaching and learning in STEM K16. He is currently researching on best practices in learning Dynamics, a sophomore engineering core course. The second research focus of Dr. Mativo is energy harvesting in particular the design and use of flexible thermoelectric generators. His investigation is both for the high-tech and low tech applications. In addition to teaching courses such as energy systems, mechanics, mechatronics, and production, he investigates best ways to expand cutting edge technologies to the workforce.

\section{Mr. Johnny Thien Pham, Robert Morris University}

Robert Morris University student majoring in Software Engineering (BS '21) and Engineering Management (MS '21) 


\title{
Using Nintendo Switch Development Environment to Teach Game Development and Virtual Reality (A Work-In Progress)
}

\begin{abstract}
In this initiative, Nintendo Switch development environment was chosen for teaching middle and early high school students game development. A two-day game development workshop was designed after two months of preparation and offered to twenty middle and high school students in two sections in the summer of 2019. Students were taught the basics of the Nintendo Switch development environment along with basics of virtual reality (VR), and asked to design a simple VR game. Nintendo Labo VR kits were also utilized in the workshop. This paper illustrates the design of the workshop including the features of the Nintendo Switch development environment in addition to the Nintendo Labo VR kits. The participants were given pre- and post-workshop surveys and demonstrated their products to their peers at the conclusion of the workshops. Each student was rewarded with a Nintendo Labo VR kit with the successful completion of his or her workshop. Lessons learned from these workshops including the need of increasing the duration of the workshops and feedback from the participants are also included in this paper, and will be employed in improving these workshops. The workshops will also be offered at the elementary school level and utilized in other outreach events such as Carnegie Science Center Sci-Tech Festivals and the National Engineers Week events. The paper is concluded with future possible outreach project ideas, based on the technical programming content and ability of Nintendo Switch development environment and the Labo VR kits.
\end{abstract}

\section{Introduction and Literature Review}

Nintendo Switch development environment was chosen for teaching middle and early high school students game development along with virtual reality (VR) basics, unlike most other efforts which focus on utilizing game development or gamification to teach programming or other subjects at college or high school levels. VR was also included since it is up and coming and many applications other than entertainment technology will soon utilize VR in the near future. Following section encompasses the introductory information and the literature surveys conducted relating to this work.

Researchers identified a spectrum indicating the level of involvement of the real and virtual worlds as shown in Figure 1 below [1][2]. In the case of augmented reality (AR), the virtual images are superimposed on a view of the real world to improve the user's experience by supplying additional information enhancing perception, subsequent mental processes and learning while making it more interactive. On the other hand, virtual reality (VR) or augmented virtuality is allowing the user to be immersed into the virtual world for similar reasons. Mixed (hybrid or extended) reality is a hybrid of AR and VR via immersive technology [1][2]. 
The main motivation for VR can be attributed to the entertainment sector (e.g. Sci-Fi) The driver was the desire to make computing as ubiquitous as possible by eliminating the

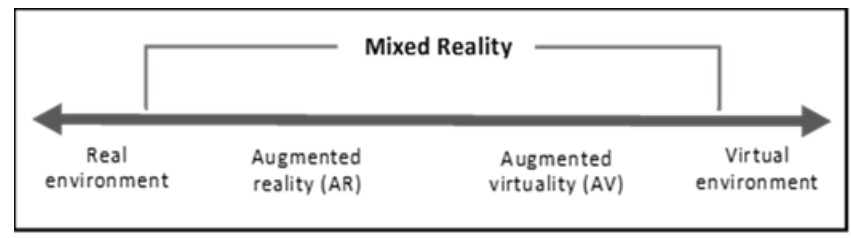

Figure 1. The reality-virtuality Spectrum - adapted from [1]

separation between the human and the computer [2]. Thus, on the early days of VR development, the main motivator was the gaming industry for creating worlds where users could immerse and role-play. However, the technology available was not good enough to support such ambitious goals. Soon after, VR and AR technology quickly evolved along with huge leaps in the available computing capabilities. Now VR and AR are considered as an important asset for various domains including industry, healthcare, education, entertainment, and many more [2]. AR/VR have great potential to be a versatile and effective industrial tool, including areas like design studies and engineering analysis, risk, accident and hazards analysis, training for safety, construction, industrial assembly/disassembly, pedestrian safety, and maintenance and service.

The literature survey conducted using the "VR game development" keywords yielded 120 ASEE conference publications over the years including subjects such as VR centered project-based learning, system usability scale for Oculus Rift and Samsung Gear equipment, use of VR in STEM e-learning, teaching drilling trajectory concepts, virtual laboratories for solar power technology. Architectural design education, engineering technology, graphics modeling and animation courses were some of the application areas found. The following section list a few of the VR publications with a game content built in. A group of authors from foreign and US universities developed a VR game for GIS learning environment [3]. The authors focused on the ownership content, stimulation of lateral thinking and problem solving as well as teamwork in their effort. A group of California State University - East Bay researchers developed a virtual reality educational game for waste management [4]. The same group of researchers also collaborated with Italian universities as they developed an educational VR game for architectural and construction review [5].

A second literature review in Scopus was conducted using the keywords "Game development" and "Education" mentioned above, yielding 95 papers, most of which are from recent years. Most of those papers identified also focused on game development at the college level [6][7], utilizing game development or gamification in teaching programming at college [8] [9] or high school level [10]. They also aimed at teaching technical subjects and even project management, following a similar pattern to the ASEE papers found, including a small number of papers with VR.

\section{Workshop for VR Game Development}

Nintendo Switch [11] [12] development environment was chosen for teaching middle and early high school students game development along with virtual reality $(V R)$. A software engineering 
undergraduate student, a co-author, under the supervision of another co-author designed a twoday game development workshop. After two months of preparation, the workshop was offered in two sections to a total of twenty middle and high school students in the summer of 2019.

Participants were taught the basics of the Nintendo Switch development environment along with basics of virtual reality (VR), and asked to design a simple VR game. Nintendo Labo VR kits [13] were also utilized in the workshop. This section of the paper illustrates the design of the workshop and the details of the development environment.

\section{Workshop Design and Its Execution}

During the first day of the 2-day workshop the participants were exposed to what VR is along with its applications including industrial and medical through a PPT presentation. Augmented reality $(A R)$ was also briefly presented with examples such as the Pokemon Go game for them to understand the differences between augmenting the real world with digital (virtual) images in the case of AR or immersion of the user as the part of the real world into a virtual one in VR. Students were told that VR will allow them to be immersed into a software application like a game allowing them to swim with sea life as they played a role within the game or another application to help train medical students as they learn to operate or understand human anatomy while navigating within. Two videos were shown to present the capabilities of the Nintendo Switch programming environment and the Labo kits. Figure 2 illustrates the sample game developed by one of the authors to explain the features of the programming environment and its graphics. Participants was then asked to construct the VR glasses and the contraptions of their choice from the Labo VR kits as shown in Figure 3. This activity took a few remaining hours of the first day.

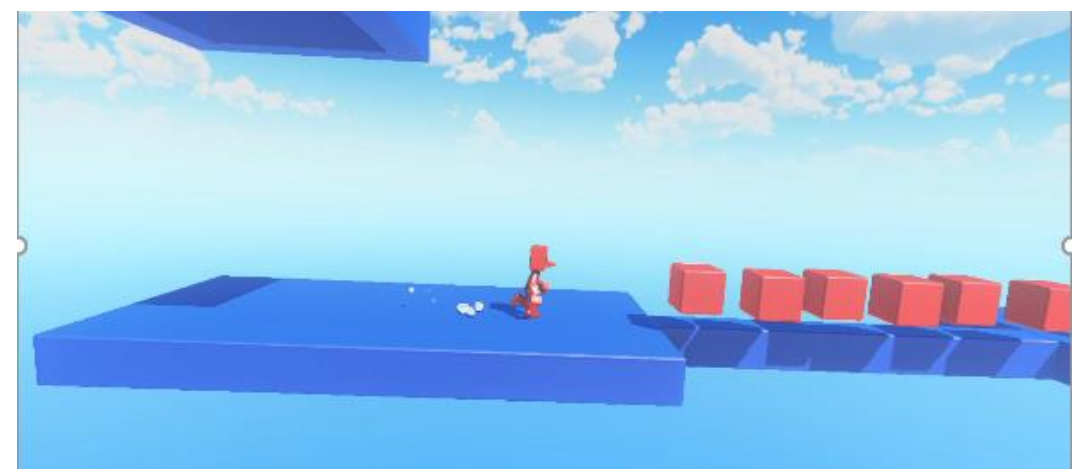

Figure 2. A sample game prepared by one of the authors.

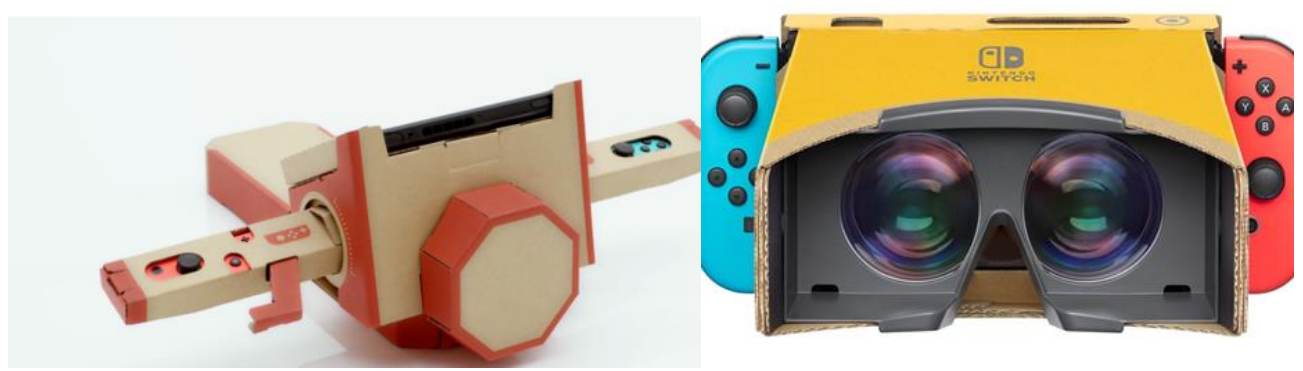

Figure 3. (a) Cardboard contraption made from a Labo kit and (b) VR glasses, both embedded within Joy-Con (red/blue) controllers 
The second day started with the review of what was taken place on the first day. The PPT presentation on Toy-Con Garage VR was given to the participants in sections with additional hands-on work taking place in between the background relevant slide sections. The following section of this paper summarizes the features of the Nintendo Switch programming environment with VR capability- Toy-Con Garage VR (which is only available within certain Labo kits). The regular Toy-Con Garage can be used in non-VR game development.

\section{Toy-Con Garage VR Environment and Game Development}

The participants accessed Toy-Con Garage VR environment through the Nintendo Switch's main menu Discover selection. After entering the Toy-Con Garage VR environment, the participants were informed about and asked to watch brief tutorials before making their own games, using the Toy-Con Garage's VR Plaza. All the sample games in VR Plaza were developed within the ToyCon Garage.

There are four menus in the Toy-Con Garage VR environment: the main menu, input, middle and output menus. The main menu is the access point to the other three. The input menu has conditions relevant to the game including various IF statements and the inputs associated with the necessary action of the game. The middle menu incorporates the game functionalities like layout, timers, counters, calculations, conversions, logic into the programming environment that can be used in placing and moving objects. The output menu exports the game into the VR Plaza mode and also performs outputs like lighting up the screen, make sounds, vibrates, and emits lights - for making game effects. After the menus are covered, a quick review on them were done by asking the participants to reflect. Similar to other computer software, the development environment has three visual display modes the Game, 3D, and 2D Views. The participants were introduced to the three display modes (Figure 4) before the game development exercises started.

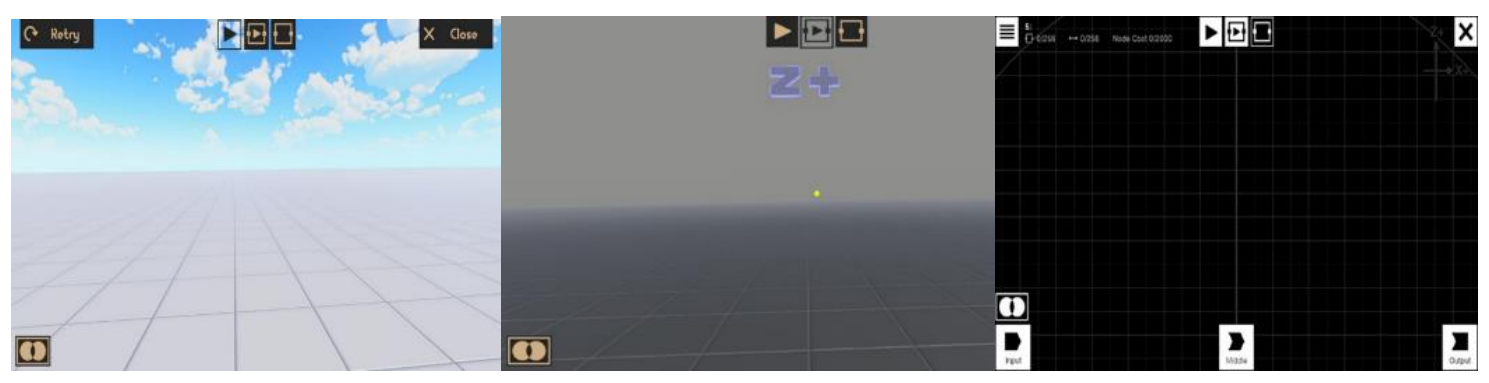

Figure 4. (a) Game, (b) 3D, and (c) 2D Views

\section{Developing a Simple Game}

Participants were taught the basics of game making as presented in this section and displayed in Table 1, followed by their own game development activity. Following sequence was conducted by hands-on activities to teach the students the requirements of game development, after a set of PPT slides relevant for each topic was covered. 


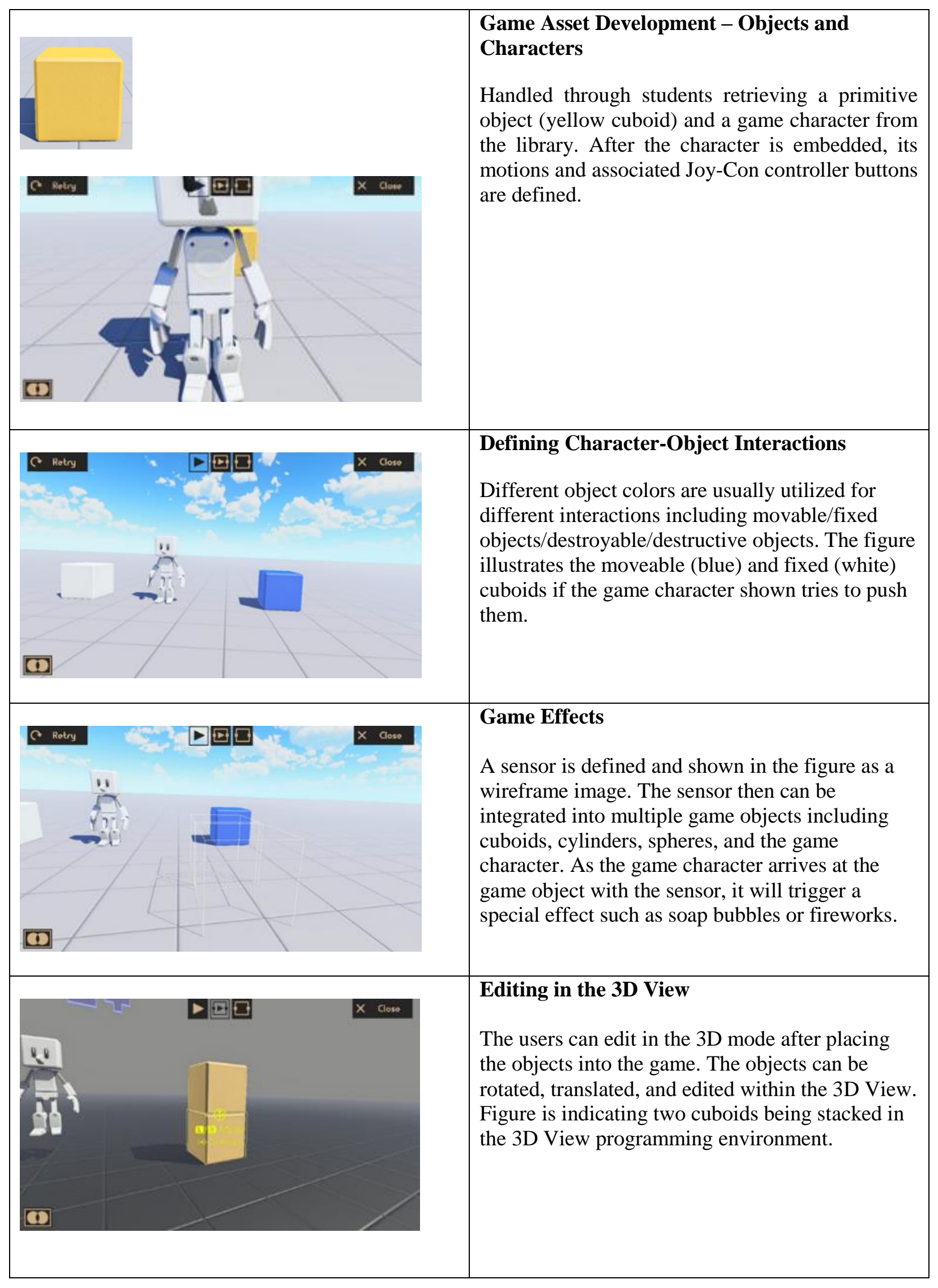




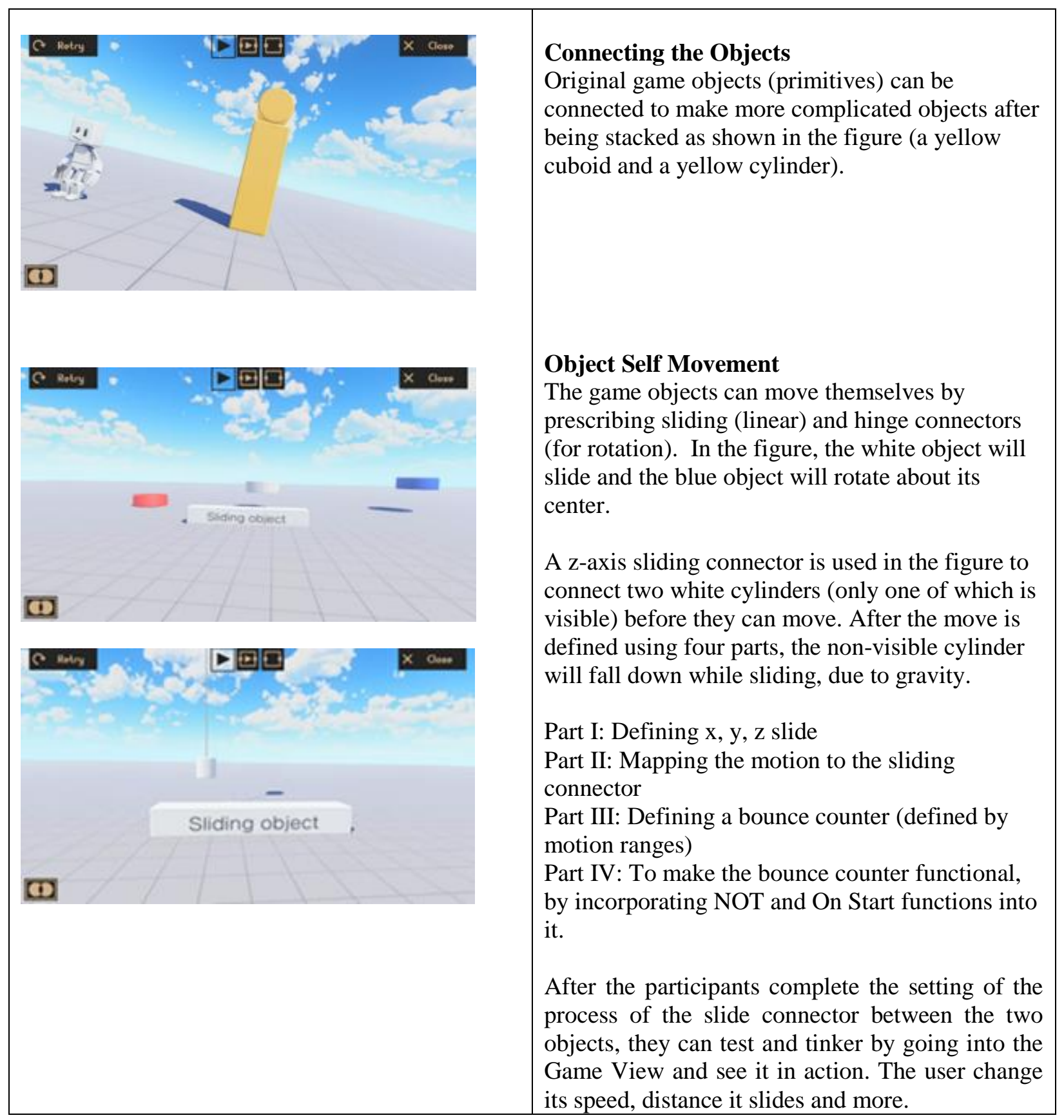

Table 1. Workshop game development sequence

Next step of the workshop was the individual student building his or her own game. The participants were asked to brainstorm and write down a few possible ideas onto a piece of paper and sketch it to visualize. After the completion of the game projects, the participants were asked to present to the rest of the class. Based on the time constraints, the students need follow a realistic idea that was feasible to complete. Additional points such as changing the camera angle from its default value, selecting the game character position and height as well as launching objects into the game, objects with visible and invisible comments and use of fancy objects were covered at the last section of the workshop. Each game requires the setting of the 
game control interfaces including the hand held mode, Joy-Con (L), Joy-Con (R), and Joy-Con (L \& R) interfaces [11][12]. Setting the Toy-Con Check function by using the Safety Cap was also presented to the students. Some of the games designed by the students will be presented in the ASEE Conference. The feedback obtained from them however, is summarized below in the conclusions section of this paper in Tables 2 and 3.

\section{Findings}

Findings of the participant experiences are shown in Tables 2 and 3 including quantitative and qualitative components with anecdotal feedback:

- Half of the 18 participants who completed their pre-and post-survey indicated that their parents informed them about the summer workshop.

- 9 indicated that they had a prior game development experience, and only 1 had participated into a VR game development experience.

- Results suggest that all of the participants were effectively engaged within the workshop. Most claimed that they had learned the basics of the game development and VR, and the associated VR hardware including the glasses.

- There was about an even split for the participants interested in the hands-on VR contraption building, and those that enjoyed the game building exercises.

- Most of the participants found the effort just right, but 2 asked for increasing the duration to more than 2 days, asked for additional instruction and help in the workshop since there was only one instructor.

- 4 of the 18 responding participants had reflected that the developing a simple VR computer game was not as easy as expected, as the others felt it was fun.

- The results also indicated that the effort strengthened the resolve for the participants to pursue a STEM field, including engineering and game development, with 14 out of the 18 positively responding.

\begin{tabular}{|c|c|}
\hline $\begin{array}{l}\text { Question } 1 \text { - Have you done } \\
\text { game development before? } \\
\text { If so, please explain. }\end{array}$ & $\begin{array}{l}\text { 1- Yes, on Scratch, using a Makey Makey board. } \\
\text { 2- Yes, Unity, Python etc. } \\
\text { 3- Yes. I have made games on Scratch and mini games on Minecraft. } \\
\text { 4- Yes, I have done ID Tech's Game Design } 101 \text { and built a level in Unreal. } \\
\text { 5- Some Scratch, not much. } \\
\text { 6- Yes. I helped at Robomatter to develop a game to teach programming. } \\
\text { 7- Yes I have done game programming. I did do a 3D game making camp a } \\
\text { couple of years ago. } \\
\text { 8- I have prepared created games on sketch before. } \\
\text { 9- Yes, on scratch.mit.edu. } \\
\text { 10- No }=9\end{array}$ \\
\hline$\because$ Yes $\|$ No & \\
\hline $\begin{array}{l}\text { Question 2- Have you done } \\
\text { VR game development } \\
\text { before? If so, please explain. }\end{array}$ & $\begin{array}{ll}\text { 1- } & \text { Yes, Google cardboard with Unity (Game Engine). } \\
2- & \mathrm{No}=17\end{array}$ \\
\hline
\end{tabular}




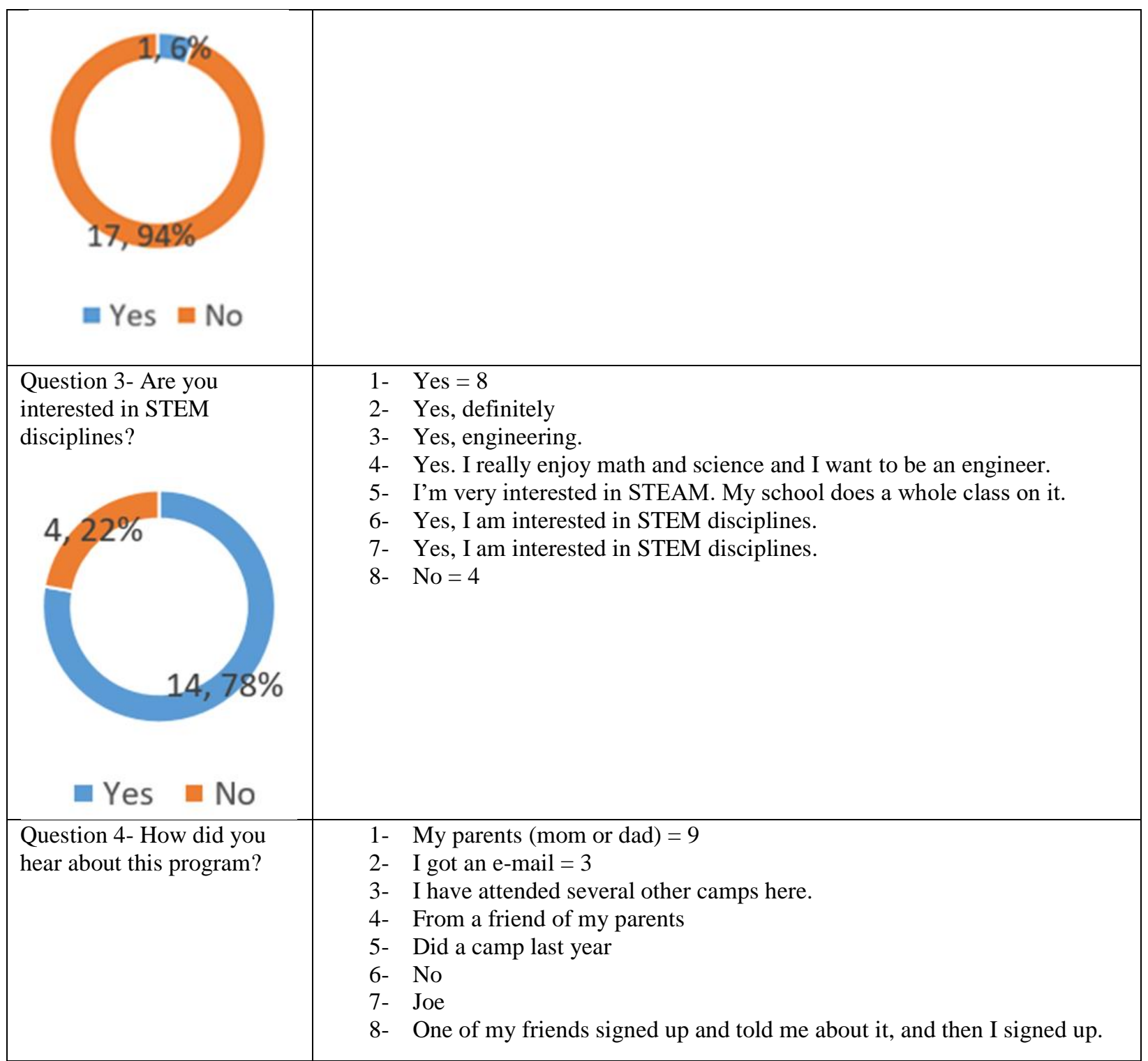

\section{Table 2. VR Pre-work-shop survey}

\begin{tabular}{|c|c|}
\hline $\begin{array}{l}\text { Question } 1 \text { - What did you } \\
\text { learn about game } \\
\text { development in the work- } \\
\text { shop? }\end{array}$ & 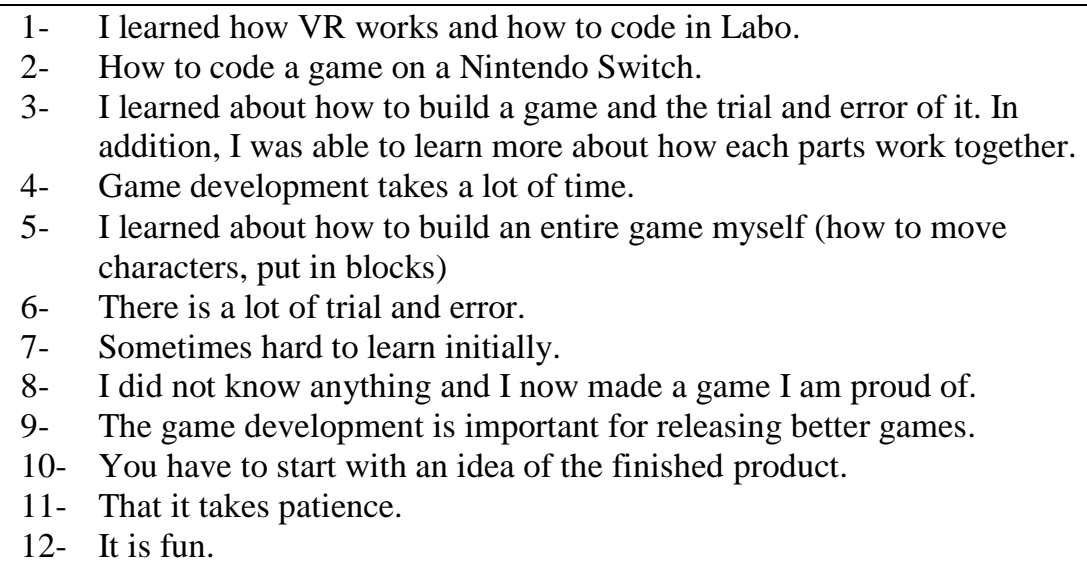 \\
\hline
\end{tabular}




\begin{tabular}{|c|c|}
\hline & $\begin{array}{l}\text { 13- I learned about the difference between AR and VR. I also learned how to } \\
\text { make games in Toy-Con VR Garage. } \\
\text { 14- There is a lot of thought that goes into creating a game. } \\
\text { 15- It takes many commands to make the program perform the way you want } \\
\text { it. } \\
\text { 16- It is hard. } \\
\text { 17- It is a lot of work. } \\
\text { 18- I learned that in order to make your character act how you desire, many } \\
\text { commands need to be programmed. }\end{array}$ \\
\hline $\begin{array}{l}\text { Question 2- What did you } \\
\text { learn about VR game } \\
\text { development? }\end{array}$ & $\begin{array}{l}\text { 1- I learned that it is interesting and details are important. } \\
\text { 2- It is cool. } \\
\text { 3- We were able to experience a VR game and understand of the } \\
\text { components of creating a game in VR. } \\
\text { 4- VR game development has an added layer of difficulty, but it is also a lot } \\
\text { more fascinating. } \\
\text { 5- VR is virtual reality and it is where you put yourself in a virtual world. } \\
\text { 6- It is easier than I thought. } \\
\text { 7- Way to add 3D parts for game. } \\
\text { 8- Same as the first question. } \\
\text { 9- The enhancement of the controller to improve the experience. } \\
\text { 10- VR is really used for making games more realistic and immersive. } \\
\text { 11- VR is much more complicated as far as movement and camera angles go. } \\
\text { 12- That it can be used for many things. } \\
\text { 13- It is fun. } \\
\text { 14- I learned about how you must take into consideration where the objects } \\
\text { and items are in 3D. } \\
\text { 15- It is very hard to create a game. } \\
\text { 16- It is challenging. } \\
\text { 17- When working with VR technology, you insert yourself into the virtual } \\
\text { world. } \\
\text { 18- It is hard. } \\
\text { 19- It is fun. } \\
\text { 20- I learned that in VR game development you are inside the virtual game } \\
\text { development. You physically feel as if you are interacting in the } \\
\text { technological world. }\end{array}$ \\
\hline $\begin{array}{l}\text { Question 3- Did this } \\
\text { workshop influence your } \\
\text { desire to study STEM? } \\
4,22 \%\end{array}$ & $\begin{array}{ll}1- & \text { Yes, but I already wanted to. } \\
\text { 2- } & \text { Yes }=8 \\
\text { 3- } & \text { Yes, it did }=2 \\
\text { 4- } & \text { Yeah, I'm a lot more interested now. } \\
\text { 5- } & \text { Strengthened desire to be a game developer. } \\
\text { 6- } & \text { Sure } \\
\text { 7- } & \text { No }=4\end{array}$ \\
\hline Yes $\quad$ No & \\
\hline $\begin{array}{l}\text { Question 4- What was the } \\
\text { most favorite part of this } \\
\text { work-shop? }\end{array}$ & $\begin{array}{l}\text { 1- } \text { Making games in VR = } 3 \\
\text { 2- } \text { The games } \\
\text { 3- We were able to learn about game development while having fun. } \\
\text { 4- I liked learning about how to make things to interact and do things like } \\
\text { make a noise in the game. } \\
\text { 5- Building the Nintendo Labo's }\end{array}$ \\
\hline
\end{tabular}




\begin{tabular}{|c|c|}
\hline & $\begin{array}{l}\text { 6- Creating the hardest platformer. } \\
\text { 7- Racing at the end } \\
\text { 8- I had so much fun with all of these people I met } \\
\text { 9- Messing around with the games on the Switch } \\
\text { 10- Making my own game (even though it was really hard) } \\
\text { 11- Building the games } \\
\text { 12- Building the things out of cardboard } \\
\text { 13- Playing the game I built. } \\
\text { 14- The building and use of the Labo. } \\
\text { 15- Building a game. } \\
\text { 16- Constructing the Nintendo Labo. } \\
\text { 17- My favorite part was creating a design that was used in the games (ex. } \\
\text { Piano, fishing, and a mortorbike). I enjoyed playing the game with VR as } \\
\text { well. }\end{array}$ \\
\hline $\begin{array}{l}\text { Question 5- How can we } \\
\text { improve this? }\end{array}$ & $\begin{array}{l}\text { 1- Class lessons to teach the basics before making games } \\
\text { 2- Make it longer }=3 \\
\text { 3- Nothing } \\
\text { 4- It is great already. } \\
\text { 5- It was perfect. } \\
\text { 6- Make it more publicized. } \\
\text { 7- May be do a } 1 \text { or } 2 \text { oral presentations for conventional games } \\
\text { 8- Nothing it is great. } \\
\text { 9- Make the camp longer. } \\
\text { 10- Have something other than pizza for lunch. } \\
\text { 11- More teachers to help control the kids } \\
\text { 12- I do not think there is anything to improve. I thought it was awesome. } \\
\text { 13- More teachers to help with the kids. } \\
\text { 14- N/A } \\
\text { 15- The camp could have been more centered on the VR technology. There } \\
\text { was extremely little exposure to the world of virtual reality. } \\
\text { 16- You can't. It is fun. } \\
\text { 18- I think that the camp should have demonstrated more exposure to the } \\
\text { actual concepts of virtual reality. }\end{array}$ \\
\hline
\end{tabular}

\section{Table 3. VR Post-work-shop survey}

\section{Extension of the Experience}

After the summer workshop, the authors applied the same approach to a couple of college level courses with a twist by asking the engineering students to design not only VR games but also 3D contraptions and printed them in place of using Labo's cardboard ones. The effort allowed undergraduate engineering students to develop games, and 3D VR equipment yielding excellent results where the educational games developed had to work with the VR equipment they also designed and built.

\section{Conclusion and Future Work}

The summer workshop engaged the participants effectively in learning game development and VR technology. Three critical observations from the workshop include: 1) a limitation of immersion time into the program. Participants observed that the 2-day time frame was insufficient for them to learn what was expected. Authors concur and have doubled the workshop 
to 4 days for similar workshops in the future. 2) inability to ascertain whether the workshop changed some students minds to pursue STEM. It is important to note that the high interest level of the participants to have careers in STEM field did not change during the workshop. However, it is important to point out there was high resolve to pursue a STEM field at the post assessment as evidenced by statements such as "Yeah, I'm a lot more interested now" and "Strengthened desire to be a game developer." It would have informative to find whether a participant view had changed. This will be done next time by coding the participant responses to matching pre-and post-assessments. 3) to reach out to parents and inform them about the upcoming workshops because it was effective method of contact for the participants.

A future workshop, to be sponsored by a local foundation for underserved student populations, is planned for 2021. Authors will incorporate experiences gained from the 2019 workshop and from the college level deployment method strategy. The workshops will also be offered at the elementary school level and utilized in other outreach events such as Science Center Sci-Tech Festivals and the National Engineers Week events.

\section{References}

[1] P. Milgram and K.Fumio, "A taxonomy of mixed reality visual displays." IEICE Transactions on Information and Systems, vol. 77, no. 12, pp.1321-1329, 1994.

[2] A. Sirinterlikci and J. Al-Jaroodi, "Industrial applications of AR", in Digital Bridge Conference, October ?, 2018, Pittsburgh, PA.

[3] M. Chandramouli, T. Lei, T. Chou, Y. Huang, S.R. Kolanuvada, "Design and Implementation of GIS Virtual Learning Environments for Interactive Visualization Using Desktop Virtual Reality (VR) \& iSpace”, in ASEE Annual Conference and Exhibition, New Orleans, LA, USA, June 25-29, 2016.

[4] F. Castronovo, S. Yilmaz, A. Rao, W. Condori Jr, K. Monga, H. Gooranorimi, “Board 63: Development of a Virtual Reality Educational Game for Waste Management: Attack of the Recyclops', in ASEE Annual Conference and Exhibition, Salt Lake City, UT, USA, June 23-27, 2018.

[5] F. Castronovo, D. Nikolic, S. Mastrolembo, V. Hroff, A. Nguyen, H.P. Nguyen, S. Yilmaz, R. Akhavian, C. Gaedicke, "Design and Development of a Virtual Reality Educational Game for Architectural and Construction Reviews", in ASEE Annual Conference and Exhibition, Tampa, FL, USA, June, 15-19, 2019.

[6] C. Peng, "Introductory game development course: A mix of programming and art", in Proceedings - 2015 International Conference on Computational Science and Computational Intelligence, CSCI 2015 7424101, pp. 271-276.

[7] D. Kletenik, D. Sturm, "Game development with a serious focus", in SIGCSE 2018 - Proceedings of the 49th ACM Technical Symposium on Computer Science Education.

[8] P. Mozelius, M. Olsson, "M Learning to program by building learning games", in Proceedings of the $11^{\text {th }}$ European Conference on Games-based Learning - ECGBL, January 2017,pp. 448-455

[9] T. Jordine, Y. Liang, E. Ihler, "A new game-based learning approach for learning Java on mobile devices", Proceedings of the 10 th European Conference on Games-based Learning - ECGBL, January 2016, pp. 853-861

[10] H. Montes-Leon, R. Hijon-Neira, D. Perez-Marin, S.R.M. Leon, "Improving Programming Learning on High School Students through Educative Apps", in 2019 International Symposium on Computers in Education, SIIE 2019.

[11] "Technical specifications of Nintendo Switch processor", Available: https://arstechnica.com/gaming/2016/12/nintendo-switch-nvidia-tegra-x1-specs-speed/ [Accessed February 03, 2020]

[12] "Technical specifications of Nintendo Switch", Available: https://www.nintendo.com/switch/tech-specs [Accessed February 03, 2020]

[13] "Nintendo Labo kits", Available: https://labo.nintendo.com [Accessed February 03, 2020] 